\title{
SON DÖNEM POPÜLER TÜRK SINNEMASINDA (2000-2004) ULUSAL KÜLTÜR BAĞLAMINDA TEMA VE KONU SORUNSALI
}

\author{
Serdar KARAKAYA \\ Muğla Üniversitesi, Muğla Meslek Yüksekokulu, Radyo-TV Yayımcıllğg Programı, Dr.
}

\section{THEMA AND SUBJECT PROBLEM CONCERNING NATIONAL CULTURE IN THE LATE PERIOD POPULAR TURKISH CINEMA (2000-2004)}

Abstract: Since its early days, Turkish Cinema has always faced dozens of problems such as censorship, unindustrialization, competition with television, creative scenario writing and acting.

The sterility problem in theme and subject matters that emerged in the 1980s has reappeared lately. It has been observed that filmmakers who struggle to exist in the Turkish Cinema sector, trusted into a serious sterility problem in theme and subject matters.

In this study, we are going to focus on this phenomena that Turkish Cinema has experienced; and by evaluating the theme and subjects on the bases of films, we are going to identify the predominant theme and subjects that Turkish Cinema inclined in this period of five years. Consequently, we are going to analyze the reasons of this inclination and try to conclude with some suggestions.

Keywords: Subject, Theme, Popular, Period, Cinema

\section{GİRIS}

Doksanlı yıllar, özellikle ikinci yarısı Türk sineması için umutların yeşerdiği, film ve seyirci sayısının arttığı, yeni salonların açıldığı, sinemanın her alanında hareketlenmenin yaşandığı umut yılları olmuştur. Nicelikte yaşanan bu sıçrama niteliğe aynı oranda yansımamış olsa da umut veren bir tablo yaşanmıştır.2000'li yıllara girildiğinde, bu ivme yerini tekrara bırakmaya başlamış, özellikle içerik ve temalarda ciddi sıkıntıları işaret eden seyirciyi "ne pahasına olursa olsun" salona çekmeye çalışan yapımlar ağırlık kazanmıştır. $\mathrm{Bu}$ olgu, doksanlı yıllarda tırmanışa geçen Popüler Türk sinemasının iki binli yılların ilk yarısında tıkanışına işarettir.

Dönemi ve filmleri ele almadan önce bir kavram ve olgu olarak popüler sinemayı açmak, yeniden tanımlamak gerekiyor; Popüler Sinema popüler kültürün içinde yer alan, onun yarattığı bir olgu kuşkusuz. Bu sinema anlayışı kendi kurallarını oluştururken popüler kültürün temel özelliklerine paralel davranır. Gündelik

\author{
SON DÖNEM POPÜLER TÜRK SINNEMASINDA (2000- \\ 20004) ULUSAL KÜLTÜR BAĞLAMINDA TEMA VE KONU \\ SORUNSALI
}

Özet: Başlangıcından bugüne Türk Sinemast; sansür, endüstrileşememe, televizyonla rekabet, yarattcı senaryo, oyunculuk, salonsuzluk ve buna benzer onlarca sorunla var olagelmiştir. Bu sorunlarn kimi zamanla etkisini yitirmiş zamanla arttırmışttr. Bununla beraber endüstrileşememe ve gösterim sorunlart da artarak sürmektedir. Son dönemde ise 1980'li yullarda bas gösteren tema ve konu kısurlığı sorunu yeniden nüksetmiş, Popüler Türk Sinemasında var olmaya çalışan yaptmct-senarist ve yönetmenler ciddi bir tema ve konu kısırlığına saplanmustır. Bunun sonucu olarak; Popüler Türk Sinemast kendi toplumundan ve ulusal kültürden uzaklaşmıs, 'bize' ait olmayan, 'bizi' anlatmayan hikâyelere yönelmiştir.

Sinemactnın temel çııs noktast egemen Hollywood yapımlart ve yaylmact kültür haline gelmistir.

Bu çalışmada Popüler Türk Sinemasının yaşadığı bu olgu ana hatlartyla irdelenecek, filmler bazında tema ve konu değerlendirmeleri yaptlarak beş ytl kapsayan bu dönemde sinemamızın yöneldiği egemen tema ve konular ortaya çıarılacaktır. Bu yönelişin nedenleri üzerinde durulup sonuৎ bölümünde önerilere değinilecektir.

Anahtar Kelimeler: Popüler, Yapım, Kültür, Sinema, Yöneliş

yaşamın kültürü olan popüler kültür dar anlamıyla emeğin gündelik olarak yeniden üretilmesinin bir girdisi olarak "eğlenceyi" içerir. Geniş olarak tanımlandığında ise belirli bir yaşam biçiminin ideolojik olarak yeniden üretilmesinin ön koşullarını sağlar [1].

Sinema ve televizyon, popüler kültürün "fazla düşünme, çabuk tüket" mantığına uygun araçlar sunar. Sorun, sinema ve televizyonun eğlenceli temalar sunması değil, bütün temaların eğlence olarak sunulmasıdır [2].

Nilgün Abisel'e göre popüler sinemanın varlık sebebi; var olan toplumsal düzenin sürdürülmesidir. Bunu yaparken karmaşık ilişkiler ağını kullanır. İzleyiciteknoloji-endüstri-sanatçı süzgecini kullanır. $\mathrm{Bu}$ açıdan bakıldığında popüler filmler özünde tutucudur [3]. Türkiye toplumu doksanlı yıllarda televizyon yayınlarının özelleşmesi/yaygınlaşmasıyla birlikte yoğun biçimde popüler kültürün etkisi altında kalmıştır. Özellikle seksenli yıllarda doğan yeni kuşak bu kültürün yıkıcı etkilerinden fazlasıyla nasibini almıştır. Ahmet Oktay'a göre; Popüler kültür biçim olarak fazla karmaşık değildir. 
Dolaylı yoldan aktarılır ve iletilir. Yaratıcısı, kaynağı anonim değildir. Açık biçimde bilinir. Toplumun temel yapısını oluşturan gelenekler ve değerler sistemi yeniden formüle edilerek sunulur. Çabuk ve kolay tüketilir. Elde edilmesi, ulaşılması, satın alınması kolay, ucuz, zaman zaman bedelsizdir. Popüler kültürün seksenli yrllarda hızlanan göçle çok yakun ilişkisi vardır. Kente gelen ama kentlileşemeyen nüfus kendi alt kültürünü yaratmıș ve tüketmeye başlamıştır. Göç kökenli nüfus yıllar içinde sınıf atlamaya başlamış ve kent kültürünün karşısına çıkarak kendi yarattığı kültürü dayatmaya başlamıștır. Üst kültür, bu yeni olgu ve oluşumlara karş1 alt kültürü (Popüler kültür) olumsuzlayan, küçümseyen bir tavır içine girmiş, yarattığı televizyon kahramanlarıyla popüler kültürü aşağılamaya çalışmış, popüler kültür öznelerini itip kakmaya çalışmış ancak süreç içinde başarılı olamadığı gibi bu kültüre teslim olmuştur. Şimdi "popüler kültür zamanı" dir. Televizyonlar, gazete ve dergiler, kitaplar ve müzik bu kültüre teslim olmuştur. Elbette ki Türk Sineması da popüler kültürden tümüyle teslim olmasa da nasibini fazlasıyla almıştır. Oğuz Adanır'a göre, Türk Sinemas1 Türk toplumunun gerisinde ve uzağında kalmıştır. Türk Sineması her şeyden önce Türk insanını anlatmalıdır. Kendi toplumunu ve ulusal kültürü çağdaş bir sinema anlayışıyla ele alıp anlatabilmelidir [4].

Kültürel erozyonun kökeninde ağır ve çok yönlü bir kültür yayılmacılığı yatmaktadır. Bülent Görücü ve Zahit Atam'a göre;

"Avrupa ve Amerikan Sinemalarmın etkisiyle, Türk Sinemasının kendine konu aldığı olayları demode olarak görmesi, dil olarak bu sinemaları model alması bir 'kültürsüzleşmeye' yol açmıştır.Sonuçta ortaya çıkan filmlerin toplumsalda karşıllı̆ı yoktur.." [5].

Doksanlı yıllarda başlayan popüler sinema etkileri iki binli yıllarda (yazının başında söz ettiğim) öteki sinemayla yan yana var olmaya çalışmış̧ır. Bu filmlerin yapım-dağıtım-gösterim koşulları eskiye oranla kısmen düzelmesine karşın, içerik bakımından yaşanan erozyon o oranda artmıştır. 2000-2004 yılları arası beş yıllık dönemde ele alınıp tek tek incelenecek filmler popüler sinema tanımına uygun, seyirci önüne çıkmış ve bu çalışmanın başlı̆ında yer alan tema ve konu bakımından sorunlu filmlerdir. Filmler, sinema gösterimlerinin yanı sira DVD, CD formatlarinda tekrar izlenerek değerlendirme yapılmıştır.

Popüler Türk Sinemasının örneği olup tema ve konu (içerik) bağlamında belirgin nitelikler taşıyan filmler de vardur. Örneğin; "Herşey Çok Güzel Olacak" (2000 / Ömer Vargı), "SSellale" (2001 / Semir Arslanyürek), "İnşaat" (2003/Ömer Vargı), "Mustafa Hakkında Herşey" (2003/Çağan Irmak) gibi filmler, popüler sinema özellikleri taşımakla birlikte belirgin bir temakonu tutarlılı̆̆ gösteren, içerik bağlamında özentiden uzak yapımlardır. Bu filmleri ayrı tutmak, farkhllıklarını vurgulayarak üzerinde durmak ayrı bir çalışmada yapilabilir.

Ele alınan filmler, yapım koşulları, sinematografi, oyunculuk, reji, dağıtım koşulları, izleyici sayıları ve diğer bağlamlarda incelenmeyecek, yalnızca bu çalışmanın sınırlarına uygun olarak tematik yapı ve konuları bağlamında incelenecektir.

\section{II. İKİ BİNLI YILLARDA ÇEKİLEN, TEMA VE KONU BAĞLAMINDA SORUNLU TÜRK FİLMLERİ}

VIZONTELE-VIZONTELE TUUBA: (2000/Yllmaz Erdoğan-Ömer Faruk Sorak2003/Yılmaz Erdoğan) Doksanlı yilların popüler sinema anlayışııı başlatan film olarak "Berlin İ Berlin" $\mathrm{i}$ (Sinan Çetin) kabul edersek, ikibinli ylllarda "Vizontele" (Yılmaz Erdoğan-Ömer Faruk Sorak) adlı filmi milat olarak almak olasıdır. Yapım sürecinde ve yapım sonrasında sürekli olarak kamuoyunun gündemine taşınan film tam da popüler sinemanın pazarlama tekniklerine uygun olarak çekilmeden merak edilen (ettirilen) bir olguya dönüsstürülmüştür. 1974 yıllnın Türkiye'sinde Güneydoğuda bir köyde geçen hikaye, Yılmaz Erdoğan' in kimi çocukluk anılarını da serpiştirildiği tematik bütünlüğü olmayan, ancak birbiriyle bağlantıl skeçler dizgesidir. Her bir sekansı tek başına izleyip gülmek olasıdir. Kolayca anlatılan ve anlaşılan hikayeler bir fikra formatına dönüşebilmektedir. Örneğin; Artist Fikri'nin (Cem Yılmaz) Başkanın (Altan Erkekli) odasındaki para isteme diyaloğu çabucak bir anektoda dönüşebilmekte, anlatılabilmektedir. Bir başka örnek; Kuran Kursunda çocukların kekeme hocayı atlatıp kaçtıkları sahne anlatıldığında gülüt (küçük, komik anlar, anlatılar=gag) haline gelebilmektedir. Tematik yapının bu parçalı kurgusu kuşkusuz konuyu bütünselleştirememe tehlikesi de doğurur. Olaylar dizgesine bakıldığında televizyonun görevliler tarafından getirilişi, uygun yer aranışı, yayının bulunamayışı, sonunda bulunuşu, köy halkının televizyonla tanışması... olarak giden iç-öykü ve buna bağıntılı yan olaycıklar dışında bir bütünsellikten söz edilemez. Bir an için komik sahne ve sekansların yer değiştirdiği dưşünüldüğünden çok fazla kopukluk ve anlam kayması olmayacaktır. Örneğin; sinema duvarının yıkılması sahnesiyle Deli Emin'in (Yılmaz Erdoğan) tezgahtardan takım elbiseyi yalan-dolanla alması sahnesi yer değiştirebilir. Olayların geçtiği yer, olaylar ve kişiler/karakterler bize özgü gibi görünse de bu yanilsamadan başka bir şey değildir. Ana kişiler ve karakterler birer karikatür ve çizgi roman tiplemesi olmanın ötesine geçememekte, dolayısıyla tema ve konu Türkiye toplumunun tarihsel ve dönemsel gerçeklerinden, bir düss olan sinema sanatının anlatı yapısının gereklerinden uzak kalmaktadır. Bununla birlikte film, seyirci açısından hoş, komik, izlenir, rahatlatıcı ve 'iyi' olarak tanımlanmıs ve üst düzeyde kabul görmüștür. İște böylelikle, popüler sinema hedefi tam kalbinden (seyirci) 
vurup amaca ulaşmıştır. Filmin bu ticari başarısından üç yil sonra devam filmi "Vizontele Tuuba" bu kez Yilmaz Erdoğan'ın tek başına yönetmenliği ile, aynı tema çerçevesinde, yeni karakterler ve değişen tarihsel süreçle seyirci önüne çıar. Dönem, ülkenin en acılı siyasi, toplumsal, ekonomik bunaliminın yaşandığı ve 12 Eylül darbesine çok kisa bir sürenin kaldığ 1980 yilının yaz aylarıdır. Kasaba iki siyasi görüşün egemenlik kavgasına sahne olmaktadır. Deli Emin kasabaya sürüler kütüphane memurunun kızinı sevmektedir. Olaylar sürüp gider. Derken 12 Eylül gelir.

Film, tıpkı birincisinde olduğu gibi epizodik anlatımla, karikatürize tiplerle, bir büyük toplumsal dönüşümü, karanlık 12 Eylül rejimine giden zorlu süreci sömürerek, sözde 'dönem eleştirisi'ne soyunmaktadır.

Özetle "Vizontele" ve "Vizontele Tuuba" filmleri tema ve konu bakımından sikıntıları olan ancak; iyi pazarlanmıs, ileri sinema teknikleri kullanilmış, popüler oyuncular üzerine kurulu, birbirinin tema ve konu olarak devamı skeç-kolaj bir filmlerdir.

HEMŞO: (2000/Ömer Uğur) Cebrail'in (Okan Bayülgen) babası yirmi yıl önce Yaşar (Mehmet Ali Erbil) tarafindan öldürülmüştür. Ailenin bir kısmı Yaşar'ın Cebrail Tarafindan öldürülerek öcün alınmasını savunur. Cebrail İstanbul'da olduğu öğrenilen Yaşar'ı bulmak için yola çıkar. Istanbul'da Yaşar'la karşılaşır. Yaşar onun kim olduğunu ögrenir ama Cebrail farkında değildir. Çavuş lakabı Yaşar'in gerçek kimliğini saklamasını sağlar. Son derece karmaşı ilişkiler içinde serseri bir hayat süren Yaşar'in dünyasına giren Cebrail'le aralarında bir yakınlık oluşur. Sonunda Yaşar'ın kim olduğunu ögrense bile Cebrail için kan davalısı olmaktan çıkar, onun uğruna hayatıni bile ortaya koyar.

Türk sinemasının gözde temalarından 'kan davası' yüzlerce filmde, farklı yaklaşımlarla ele alınmıştır. Hemşo filminde bu tema bir "leitmotiv" gibi kullanılmış, ana öykü dostluğun ve dayanışmanın her koşulda ortaya çıabileceği savı üzerine oturtulmuştur. Cebrail'in babasının katili Çavuş lakaplı Yaşar'dan intikam alma çabası üzerine kurulu öyküde ilginç olabilme adına, iki düşman tesadüfen bir araya getirilir. Yine tesadüflerle ikilinin kaderi birbirlerine bağlı biçimde çakışır. Yaşar'ın maceralarla dolu yaşantısında Cebrail öldürmeye niyetlendiği adamın kurtarıcısı haline gelir. $\mathrm{Bu}$ zıtlik üzerine bina edilen dramatik yapı, filmin ilk yarısı için kurtaricı olsa da ikinci yarıda derin sarkmalara ve uzama duygusuna yol açar. Tema, kan davası veya ona yönelik bir eleştiri gibi görünmekle birlikte birdenbire dostluk, hayatın önemi, dayanışma gibi temalara yönelmektedir. $\mathrm{Bu}$ bakimdan bir tema bütünlügüünden söz edilemez. Yaşar'ın hayatı, çevresi, bir nevi 'utanmaz adam' tiplemesi de (Oğuz Aral'ın karikatür kahramanı) konuyu ilginç kılmaya, boşluğu doldurmaya yetmemektedir. Zorlama olaylar zinciri, tematik yapıdaki kararsızlık popüler oyunculara dayalı bu filmin ciddi zaaflarmı oluşturmaktadır.

KOMSER ŞEKSPİR: (2000/Sinan Çetin) Mizah yazarı Mesut Ceylan'ın senaryosundan filme çekilen film, popüler sinemanin bütün trüklerini kullanan bir diğer popüler yapımdır. Her bakımdan ilginç bir yaşam alanı olan İstanbul Taksim civarında bir karakola türlü nedenlerle getirilen bir grup insanla komiser Cemil, (Kadir Inanır) komiserin kanserli kız $\mathrm{Su}$ (Pelin Batu) arasında geçen hikaye, Vizontele filmindeki skeç-kolaj yapisina sahiptir. Ana karakterler ve yan tiplere dayal hikâye yer yer masalsı ögeler taşımaktadır. Dolayısıyla kişiler olayların önüne geçmektedir. Bu durum anlatıyı zedelemektedir. Konu ve konu dizgesi altmışlı yılların duygusal güldürüleriyle paralellik gösterir. Özellikle çocuk oyuncularm sömürülmesi üzerine kurulu bu hikâyelerde (Ömercik, Ayşecik, Yumurcak serileri) acıklı olaylar, komik tipler, şaşırtıcı ve beklenmedik gelişmeler ana çatıyı oluşturur. Hikâyenin önemi kalmaz, tipler ve olaycıklar öne çıkar. Sağlam bir öyküsü olmadığından finale doğru ağır bir sentimental (aşırı duygusal) yoğunluğa sığınmaktadır. Bu Film, tematik yapısı ve konusuyla basit bir fantezi denemesi olmaktan öte gidememektedir.

ABUZER KADAYIF (2000/Tunç Başaran): Seksenli yıllarda ünlenen pop-arabesk-türkücü İbrahim Tatlıses çağrışımları üzerine kurulu, özgün bir hikayesi olmayan, uzaktan uzağa Levent Kirca-Olacak O Kadar fenomeninin anımsatan yapımda egemen söylem "yerine geçme"dir. Hollywood filmlerinin zaman zaman kullandiğı bu trük, geçici bir süre ünlü birinin, bir akrabanin, bir sevgilinin yerine geçme, kendini kamufle etme üzerine kuruludur. (Örn: "Bir Günlük Başkan", “Süpermen, Örümcek Adam")

Sosyoloji profesörü Ersin Balkan (Metin Akpınar) karısin tinerci saldırısinda kaybeder. Hayatının kalan kısmını sokak çocuklarını topluma kazandırma projesine adar. Kendisine ikinci bir yaşam ve kimlik oluşturur. Geceleri arabesk türkücü kimliğiyle büyük paralar kazanıp projeye aktarır. Geceleri ve kalan diğer zamanlarında kendi kimliğine döner. $\mathrm{Bu}$ durumu yakın dostu Abdo'dan (Talat Bulut) başkası bilmemektedir. Abdo , her türlü bağlantı ve organizasyonu kuran, sürdüren kişidir.

Tunç Başaran, sinema kariyerinde onlarca nitelikli filme imza atmuş, belirgin bir kalitenin üzerinde kalmıș yaratıcı yönetmenlerden biridir. Bununla birlikte bu yapımda, popüler kültürün sularına yelken açarak bir poparabesk ikonu olan İbrahim Tatlıses'in yaşam hikâyesi tartışmalarına kayan bir konuya ilgi duymuştur. Konusunu buradan alan bir filmde ana karakterin İbrahim Tatlises, onu 'oynayan' Metin Akpinar olunca filmin 'karikatürize' olması kaçınılmazdır. 
DELIYÜREK BUMERANG CEHENNEMİ: (2001/Osman Sınav) Popüler Türk sinemasının Hollywood ekolünden kopya ettiği bir diğer gelenek; tutulan TV dizilerinin sinema versiyonunu çekmektir. Geniş kitlelerin beğenisini kazanan dizide ana karakter Miroğlu'nun (Kenan İmirzalığlu) bireysel kahramanlıkları ana çıkış noktasını oluşturmaktadır. Bu kahraman fenomeni; sinemanın var olduğu günden bu yana kullanıla gelmiş, klişeleşmiş, hayatta karşılığı olmayan, olağanüstü yetilerle ve güçlerle donatılmış insanüstü varlıktır. Miroğlu bu $\mathrm{kez}$ güneydoğudadır, ülkenin yirmi yıldır yaşadığı acılı geçmişle doğru düzgün bir bağı olmayan olaylar dizgesi içinde ortada kahramanlık taslamaktadır. Filmde olan bitenin toplumsal gerçekle (ki Türkiye toplumumum son yıllarda yaşadığ en kaotik ve en acılı sorunu güneydoğu sorunudur) paralel giden, tutarlı hiçbir yanı yoktur. Evet; sinema bir kurmaca sanatıdır, hayal gücüne dayanır. Ama, sinemacinın var olan bir toplumsal tema üzerine kurgusal bir hikaye oluştururken, realiteden uzaklaşma lüksü de yoktur. Konuya yaklaşım bakımından 'Deliyürek Bumerang Cehennemi' filminin taraf olma gibi marazi bir tutumu ve gerçeğin dışına kayma handikapı vardır. Film, tematik yapısı ve konuya yaklaşımı bakımından taşıdığı tüm çarpıklıklara karşın TV dizisinde olduğu gibi büyük oranda ilgi görmüş ve popüler sinemanın birincil amaçlarından olan gişe yapma amacını yerine getirmiştir.

YEŞiL IŞIK: (2001/Faruk Aksoy) Popüler Türk sinemasının son dönemdeki en kötü performanslarından biri olan filmde ne tema ne de konunun tutarli bir yanı yoktur. TV yarışma programı ile ün kazanan Kenan Işık ile popüler bir figür olan Hülya Avşar'a sırtını dayamaya çalışan fantastik denemede, zamanı gelmeden öldüğü anlaşılan bir adamın tekrar dünyaya dönüşü, bağışladığı organlarını tek tek toplayışı, ancak kalbini bağışladığı Avşar'a aşı olup çıkmaza girişi anlatılır. Ulusal Sinema anlayışının tartışıldığı, film yapımının bin bir emek ve para gerektirdiği bir sinema ortamında bu kısa özet bile filmin tema ve konu olarak gereksizliǧini anlatmaya yetmektedir. Fantastik sinema yapmaya soyunan sinemacının düş gücü bu denli kısır ve kısa yolcu olmamalıdır. Aşkın yüceliğini, aşk için neler yapılabileceğini söylemek için bu cılız ve inandırıcılıktan uzak hikâyeye ihtiyaç duyulmamalıdır. Zamanda yer değiştirmek, öldükten sonra hayalet olarak geri dönmek, ruhlarla bağlantı kurmak gibi temalar bir tür olan Fantastik Sinemanın evrenindedir, Türkiye toplumuna ve seyircisine yabancı temalardır. Ne var ki, Hollywood ürünü binlerce Fantastik Sinema örneğinin seyircide beklenti yaratmış olabileceği düşüncesinden hareketle bu filmin tutacağını öngörmek tek kelimeyle yanılgıdır.

KOLAY PARA: (2002/Hakan Haksun-Ercan Durmuş) Doksanlı ve iki binli y1llar Türkiye'sinin yükselen değerleri; 'ne olursa olsun para kazanmak, bir şekilde yırtmak' filmin ana çıkış noktasını oluşturuyor. Bir tema olarak ilk bakışta önemli ve kayda değer olan bu başlıklar, sağlam bir konu ve iyi örülmüş bir senaryo ile desteklenmedikçe içi boşalıp basitleşmektedir. Öykü, tıp fakültesi öğrencisi Eray (Emre Altuğ) ve aynı evi paylaştığı arkadaşları Servet (Mustafa Uğurlu) ve Güven'in (Okan Yalabık) yaşadıkları üzerine kuruludur. Üçü de parasız, zor koşullarda yașayan, geleceğe ilişkin kırık dökük planları olan birer 'tutunamayan'dır. Eray fizik avantajiyla fotomodellik, oyunculuk, șarkıcilık gibi alanlarda şansını zorlamaktadır. Servet, her türlü dalaverenin içinde, küçük üç kâğıtlarla bıçak sırtında yaşamaya çalışmaktadır. Güven'in kimya fakültesinde okuyan bir arkadaşını da işin içine sokarak sahte viski üretimine girişirler, ancak işler umdukları gibi gitmez, aldıkları avansı batırılar, mafya peşlerine takılır, Eray eski kız arkadaşıyla karşılaşır, kadın evlenmiştir ama tekrar birlikte olurlar, kadın olaylara karışır..

Anlaşılan o ki; filmin senaryosunu da yazan Hakan Haksun-Ercan Durmuş ikilisi B sinffi Hollywood yapımlarından ve çizgi roman maceralarından fazlasıyla etkilenmiştir. Eray ve arkadaşlarının başlarına gelenler, olay örgüsü, ana kahramanlar ve yan tipler inandırıcılıktan uzaktır. Köşe dönme, tatlı hayat, bol para kazanma, firsatçıllk gibi tam da döneme uygun, uygun temalar üzerine bu denli sığ bir hikaye kurup, zayıf bir dramaturji ile sinemalaştırmak, vasatın üzerine çıkmak için kaçırılmış bir firsattır.

MUMYA FIRARDA: (2002/Erdal Murat Aktaş) Türkiye-Mısır ortak yapımı film, gizli servis ajanı Ahmet'le (Teoman) Misırlı Fatima'nın (Nurgül Yeşilçay) karmaşık maceraları ve ilişkisi üzerine kurulu. Ahmet, köklü bir ailenin fotoğrafçıllk yapıyor görünen ama Milli İstihbarat Teşkilatının görevlisi olan oğludur. Fatima ünlü bir arkeoloji profesörünün üniversitede okuyan kızıdır. İki gencin yolu bin yıllık bir mumyanın Misırdan Türkiye'ye kaçırılması serüveninde kesişir. Kaçırılan mumya bir mafya babası için toz haline getirilip afrodizyak olarak kullanlacaktır. Ancak Türkiye'ye gönderilen iki tabut alanda karışır. Birinde mumya diğerinde arkeolojik kazılarda ölen birinin cesedi vardır. Olaylar tam bir kaos, kovalamaca biçiminde gelişir. Gizli ajanlar, beceriksiz polisler, aşıklar, mafya üyeleri arasında sürüp giden kovalamaca, patlayan arabalar, vurulanlar, kaybolanlar, garip olaylar sürer gider.

Bu kısa özet bile filmin ucuz bir macera-komedi türünde olduğunu anlamaya yetmektedir. $\mathrm{Ne}$ oyuncularının popülaritesi, ne yüksek prodüksiyon maliyetleri seyircinin yabancı olduğu temalara-konulara ilgi uyandırmaya yetmiyor. Hollywood yapımı dev prodüksiyonlu, gösterişli 'The Mummy'(2001-Stephan Sommers) ve devam filmi 'Mumya Dönüyor' (2002) adlı filmlerle aynı döneme rastlayan yapımın konu olarak Türkiye sinema seyircisini 'Türk Filmi' bağlamında ilgilendiren bir yanı yoktur. Bu filme Türk sineması seyircisinin ilgi duyacağını beklemek daha en başta maça 1-0 yenik başlamak anlamını taşımaktadır. Komedi- 
macera kuşkusuz bir sinema türüdür. İyi yapıldığında keyif verir. Sinemanın sanat olmaktan başka aynı zamanda bir eğlence (entertaintment) olduğunu unutmamak gerekir. Mumya Firarda filmi, temastyla ve konusuyla seyircisinden çok uzağa düşmüş bir filmdir.

ASMALI KONAK/HAYAT: (Abdullah Oğuz) Popüler TV dizisi Asmalı Konak'ın tema ve konusu aynı kalmakla birlikte sinema filminin gereklerini yerine getirmek adına ana hikayenin üzerine yerleştirilen yeni olaylar dizgesiyle durum kurtarlmaya çalış1lıyor. Tutan bir televizyon dizisinin sinema versiyonu çekilirken temel çıkış noktası 'hazır seyirci'dir. Batı sineması ve Avrupa Sinemasinda da örnekleri görülmektedir.(Örn: "The Fugitive-Kaçak"1993 Yön: Andrew Davis) Türk televizyon tarihinin en ilginç fenomenlerinden biri olarak 'ağalı-konaklı' dizi söylemini yaratan serinin en önemli ayağı olan Asmalı Konak dizisi konusuyla, oluşturduğu seyirciyle kapsamlı bir sosyolojik araştırmanın alanına rahatça girebilir. Filme eklenen olaylar dizisi filmsel dinamiği arttırmaya dönük, sinematografiye yeni bir soluk getirmeyen eklentilerdir. Bir anlamda dizinin finali gibi sunulan film yeni bir soluk getirmeden, bir sinema filmi olmanın uzağında dramaturjisiyle sadık izleyici kitlesini (TV için izleyici, sinema için seyirci demenin artık bir zorunluluk haline gelmesi gerekiyor) sömürmüştür.

OKUL: (2003/Yağmur-Durul Taylan) Türk sinemasının zaman zaman el attığı türlerden biri de korku ve gerilim türüdür. $\mathrm{Bu}$ denemeler sınırlı sayıda seyirci tarafindan ilgi görmüss, Türk sinemasında bir gelenek oluşturamamıştır. Türk sineması tarihine baktığımızda; "Çı̆̆lk" (1949/Aydın Arakon), "Drakula İstanbul'da" (1953/Mehmet Muhtar), "Görünmeyen Adam İstanbul'da" (1955/Lütfi Akad), “Ölüler Konuşmaz ki" (1970/Yavuz Yalınkılıç), "Şeytan" (1974/Metin Erksan) gibi örneklere rastlanmaktadır.

Türk sinemasının korku türüne yeterince ilgi duymaması ve türde az sayıda film üretmesinin temel nedeni yapımc1-yönetmen ve senaristlerin korku sinemasının ticari anlamda başarısız olabilecekleri yönündeki kaygılarıdır. $\mathrm{Bu}$ kaygılar günümüzde de sürmektedir.

Taylan Kardeşlerin korku türüne ilgi duymalarının altında, olasılıkla, beslendikleri ve çokça etkilendikleri Hollywood yapımları ve yönetmenleri yatmaktadır. Hollywood Sinemasının en gözde temalarından gençlikkorku-gerilim temaları binlerce kere kullanılmış, türün alt-kategorileri oluşmuş, fenomene dönüşmüș kahramanları, devam filmleri eski-yeni kuşakları etkilemiş, etkilemektedir. Türün vazgeçilmez trükleri ise;gizemli mekanlar, kimliği belirsiz seri katiller, kaybolan kişi veya nesneler, karanlık ve izbe binalar, zombiler, hayaletler, kaçıp kovalamacalar, intikam, en masum görünenin katil çıłkması, en kuşkulunun masum çıkması, işbirlikçinin mutlaka ölmesi, takip edilme, tekinsizlik, yardım alamama, kasvetli ve kötülüğü haber veren gizemli adamlar vb..olarak suralanabilir.

Okul filmi, bu trüklerin bir kısmını çok acemice ve hoyratça kullanmaya çalışmaktadır. Konuyu kısaca hatırlarsak; olaylar İstanbul'da bir lisede geçer. Okulun içe kapanık, romantik karakterli öğrencisi ve ayn zamanda Okul Gazetesinin editörü Gökalp (Burak Altay), Güldem'e (Nehir Erdoğan) marazi bir aşkla bağlanmıştır. Gökalp, Güldem'in ilgisini çekebilmek için bu aşkı anlatan hikâyeler yazarak okul binasında çeşitli yerlere bırakmaktadır. Ancak, aşkına hiçbir karşıllk bulamaz. Ardinda gizemli bir mektup birakarak intihar eder. Aradan bir yıl geçmiştir. Gökalp'ın ölüm yıldönümünde okulda garip olaylar başlar. Bir yandan da yaklaşan ÖSS sinavları gençleri đüş̧ündürmektedir. Herkes yaşanan bu garip olaylardan fazlasıyla etkilenecektir. Güldem'in erkek arkadaşı Ersin (Berk Hakman), yakın arkadaşlanı Şebnem (Sinem Kobal) ve Ceyda (Melisa Sözen), diğer öğrenciler, öğretmenler ve okul müdürü bu süreçte hedefteki kişilerdir. Çünkü Gökalp'in hayaleti geri dönmüş̧ür ve intiharında payı olan bu kişilerden tek tek intikamun alacaktır.

Türk toplumunun kuşkusuz kendine özgü bir korku kültürü geleneği vardır. Cinlerin insanlara musallat olması, cin padişahları, gulyabaniler, kurşun dökme, büyü yapma, büyü bozma, şeytan kovma, üfürükçülük, fala bakma, rüya yorumları, hurafeler, nazar, kerametler, peri efsaneleri, mezarlık hikâyeleri, bunlardan yaygin ve ilk akla gelenler. Ama Türk toplumunun ortak belleğinde hayaletler, lanetlenmiş kasabalar, ruhlar tarafindan ele geçirilmiş evler, cadılık, kasvetli kiliseler, kehanete dayalı kötülükler, zombiler, reenkarnasyon ve bunlarm alt temaları batı toplumlarına ve Hiristiyan kültürüne özgü kavram ve olgulardir. Dolayisiyla Hollywood Sinemasının da en gözde temalarıdır. Durul ve Yağmur Taylan'ın açık ve net biçimde Hollywood korku-gerilim sinemasindan fazlasıyla etkilendikleri ortadadır.

\section{SONUÇ}

Son yirmi yıla bakıldığında Türk sineması büyük bir değişim ve dönüşüm içindedir. Bu değişim ve dönüşümü "farklılaşma" olarak algılamak gerekir. Yapımdağıtım koşulları, televizyonun etkileri, yeni perspektifler, batı ve batı dışı sinemalarla etkileşim, endüstrileşemeden artş̧a geçen film üretimi, oyunculuk anlayışı ve yeni oyuncu kuşağ 1 bu "farklılaşmanın" temel başlıklarından birkaçıdır. Tema ve konu bakımından yaşanan sıkıntı bu dönemin öne çıkan özelliklerinden biridir. Bu dönemin bir ara periyodu olan iki binli yılların ilk yarısında; Popüler Türk sineması örneklerinin bir kısminda, tema ve konu seçiminde ulusal kültürden uzaklaşma, inandırıcı olamama, yapaylık, sığlık ve özenti göze batmaktadır.

Doksanlı ylllarda ülkemize gelip yerleşen, sinema salonlarına adeta el koyan dev Hollywood şirketlerinin 
istilasıyla, Türk sineması zaten az olan seyircisini yayılmacı sinemaya ve onun dayattığı kültüre kaptırmıștır. Seksenli yıllarda doğan ve popüler kültürün egemenliğinde büyüyen kuşak sinema seyircisi olarak salonlara gittiğinde, etkisi altında kaldığı, Hollywood sinemasının ve kültürünün "benzerlerini" görme isteği duymaktadır. Sinema hazzı bu kuşak için başkaca bir anlam taşımaz. Bu dönemde böyle bir seyirci kuşağ yaratılmıştır. Farklılaşmanın bir boyutu da budur.

Doksanlı y1llarda yetişen, popüler sinema kulvarında film yapan yapımcı ve yönetmenler için hedef kitle bu seyircidir. Seyirci gibi, yapımcı yönetmenlerin bir kısmı da öykünmeci bir anlayıșın etkisindedir.

Tema ve konu sorunsali, farklı bir sinema anlayışının izini süren, popüler sinemanın dışında arayış sineması olarak tanımlayabileceğimiz kulvarda yürüyen sinemacılarda ve ürettikleri filmlerde de vardır. $\mathrm{Bu}$ ayrı bir çalışmanın konusudur.

Sonuç olarak baktığımızda; iki binli yıllarda çekilen popüler Türk sineması örneklerinden bir kısmı tema ve konu bağlaminda sorunlu filmlerdir. Yapay ve öykünmecidirler. Ancak, öykünme zararsızdır. Gelip geçicidir. Türk sinemasının popüler kulvarında : bu denemeler de olmalıdir. Her yapimci ve yönetmen olanak buluyorsa bu janr'ın izinden gidebilir. Bilinmesi gereken; korku ya da başka temalarda film yapıp kalıcılık hedefleniyorsa, öncelikle Çağdaş ve Klasik Türk Edebiyatına, zengin bir birikime sahip anonim kültüre derin bir perspektiften bakılmalıdır. Korku, kahramanlık, ihanet, bağlllık, kara sevda, yeniyetmelik, eşcinsellik, aile,milliyetçilik, dinler, tarikatlar..ve daha onlarca tema, konu oradadır. Türk sineması diğer sorunlarını aşarken olduğu gibi, tema ve konu seçiminde de ulusal değerlere ve ulusal kültüre yabancllaşmamalı, evrensel değerlere ve evrensel kültüre uzak kalmamalıdır.

\section{YARARLANILAN KAYNAKLAR}

[1] Batmaz, V. (1991). Popüler Kültür Üzerine Değişik Kuramsal Yaklaşımlar. Istanbul Üniversitesi Iletişim Fakültesi Dergisi, (3), 66-68.

[2] Postman, N. (1994). Televizyon, Öldüren Eğlence. İstanbul: Ayrıntı Yayınları.

[3] Abisel, N. (1995). Popüler Sinema ve Türler. İstanbul: Alan Yayıncilık.

[4] Adanir, O. (1987). Sinemada Anlam ve Anlatım. Ankara: Kitle Yayınları.

[5] Görücü, B. \& Atam, Z. (1995). Yeni Dünya Düzeni ve Sinema. Görüntü Dergisi, (3), 16-19.

Serdar KARAKAYA (serdarkarakaya62@hotmail.com) has received his Ph.D. from İstanbul University Social Sciences Institute. He is instructor at Muğla University. His research areas include Turkish Cinema history, film making, broadcasting and media. 